\title{
Developments on Informatization Technology in Agricultural Operations in China
}

\author{
Qiuping $\mathrm{Zhou}^{1}$ and Guohua $\mathrm{Fu}^{2, *}$ \\ ${ }^{1}$ College of Agriculture, Hainan University, 570228, Haikou, Hainan, China \\ ${ }^{2}$ Hainan University, 570228, Haikou, Hainan, China \\ zop5545@126.com, fgh328@163.com
}

\begin{abstract}
Eleventh Five-Year" period of China's agricultural and rural information construction achieved important results in significant improvement in the information base. "Twelvth Five-year" period, agricultural and rural information environment for the development of more optimized, more urgent needs, some of the outstanding issues to be resolved, agricultural and rural information construction is about to enter a new historical stage of development, facing a major opportunity, the task is arduous.
\end{abstract}

Keywords: Summary, Informatization technology developments, Chinese agricultural operations.

\section{Introduction}

Under the leadership of the CPC Central Committee and the State Council, in close cooperation with community, the Ministry of Agriculture tightly around the development of modern agriculture and the goal of building a new socialist countryside, continue to implement projects; market and Economic Information Division set up at the information technology to promote, specifically responsible for promoting national agricultural informatization work in rural areas. China's agricultural and rural information construction progress is significant, the deepening of the field of application of information technology in agricultural production, the rapid development of information technology in agricultural operations, agricultural management information to further promote agricultural services information technology steadily improved, "Twelve Five" period of national agricultural the smooth development of the rural informatization work has laid a good foundation.

\section{Agricultural Products Logistics Informatization}

Comprehensive information technology to promote agricultural super-docking. Ministry of Agriculture, vigorously promote the information construction in agriculture super-docking process, the implementation of grading and packaging of agricultural

\footnotetext{
* Corresponding author.

D. Li and Y. Chen (Eds.): CCTA 2013, Part I, IFIP AICT 419, pp. 10-15, 2014.

(C) IFIP International Federation for Information Processing 2014
} 
products and logos, specification, acquisition, storage, transportation, sales and circulation, promote the use of modern circulation technology, information technology means to establish a quality traceability system, the development of online agriculture super-docking platform to encourage the supply and demand information through agriculture super-docking system, to carry out the contract online and trading pilot, and promote agriculture super-docking, modernization. As of the end of 2010, the country has 28 provinces (autonomous regions and municipalities) to carry out the agricultural super-docking, involving more than 10 categories of agricultural products, the Products held around the various forms of trade fairs, Fair more than 5,000 performances, there are more than 2,000 retail enterprises varying degrees, to carry out agricultural super-docking, Ministry of Agriculture directly helping more than 2,000 farmers 'professional cooperatives and supermarkets agriculture super-docking, driven 11,000 farmers' professional cooperatives and supermarkets and marketing relations, promote the circulation of agricultural products cost an average of $10 \%-15 \%$ of farmers participating in the butt than undocked the farmers annual increase of $10 \%-15 \%$.

Cold chain logistics information technology to accelerate the start. China is speeding up the establishment of the main varieties and key areas of agricultural products cold chain logistics system, information into safety traceability of the cold chain logistics, temperature control and shelf life, freshness and meticulous management to provide a guarantee, but also promoted the cold chain logistics resources the rational allocation. As of the end of 2010, there were cold storage nearly 20,000, the total cold storage capacity of 8.8 million tons, exports of fresh agricultural enterprises generally the whole low-temperature control, large-scale meat slaughtering enterprises began to use international advanced cold chain logistics technology, toward the full low temperature control the direction of rapid development. Sinotrans, COFCO social third-party logistics enterprises to establish international state-of-the-art cold chain facilities and management system, Shuanghui, public goods, Bright Dairy food production enterprises to actively improve the cold chain networks, large commercial enterprises chain terminal sale of part of the continuous improvement of cold chain management, cold chain logistics enterprises in the overall network, information technology development trend.

\section{Agricultural E-commerce}

Multi-level agricultural e-commerce network system has improved constantly. The end of 2010, the National Rural e-commerce site has more than 30,000, of which agriculture-related website 6000 , led to profound changes in agricultural production, supply mode. The official website as the representative of Chinese agricultural marketing platform to further increase agricultural information dissemination efforts to close the production and sale of contact; dish housekeeper, I bought the network, as the representative of agricultural e-commerce website easy fresh fruit days with rich e-commerce business, full service online purchase, logistics and distribution, electronic payment; new Hope, love agricultural Inn as the representatives of agricultural production enterprises have self-built e-commerce platform, own agricultural 
production, supply and electronic links formed a multi-level e-commerce network system of agricultural products, some good benefits, the information environment of national and regional markets, agricultural information dissemination and active zone of the transaction.

Regional staple agricultural products electronic trading market has developed rapidly. In 2010, China's agricultural trade and circulation mode continuous innovation, have established a number of bulk agricultural commodities online trading center, relying on the Internet organize all the members of the dealer directly online quote, matching, online ordering, electronic shopping bulk buyers and sellers face-to-face spot trading of agricultural products. For example, the Shanghai staple agricultural products market mainly oilseed commodity forward transactions in the standard contract bidding exchange and spot transactions special spot transactions, combined with the online trade of agricultural products, the improvement of standards of transactions, and settlement systems and ancillary storage and logistics delivery system. In addition, Shandong Shouguang Vegetable electronic trading market, Guangdong Shun Li bulk electronic trading market of agricultural products, bulk agricultural products in Hubei electronic trading market, Changsha Southern staple agricultural products market have set up and put into operation.

\section{Agricultural Products Wholesale Market of Information Technology}

Agricultural market system has improved constantly. Ministry of Agriculture in accordance with the requirements of the "Eleventh Five-Year" period of national agricultural market system planning "to guide an orderly way around the agricultural market system. According to statistics, China has agricultural products wholesale market over 4300, on the regional distribution to achieve full coverage of the producing areas and sales areas, to achieve a comprehensive and professional complement each other on the type of market, the business scope planting livestock, aquatic products and other agricultural products is all inclusive. At the same time, the number of farmers' markets stabilized at about 25,000, a steady increase in the proportion of supermarkets in the circulation of agricultural products, agricultural futures listed species 13. Information technology as an important support for the main channel to the wholesale market of agricultural products, farmers markets and other retail terminal-based, supermarket chains and other modern methods of distribution for the pilot, the futures market to complement the modern market system of agricultural products has been basically formed.

The information of the internal management of the wholesale market, to proceed with the transaction information. Group of economically strong agricultural product wholesale markets make full use of modern information technology, the implementation of a customer management, booth management, personnel management, financial management and administration of public security information technology. Some agricultural products wholesale market to abandon the cash transactions continue for many years "paid their dues, hand delivery, electronic unified settlement (including both 
credit card transactions) way. A small number of wholesale markets of agricultural products such as Shenzhen Futian Market, Shandong Shouguang market attempts to implement electronic auction transactions; some markets also opened the e-commerce trading platform.

\section{$5 \quad$ Agricultural Enterprise Information Technology}

The agricultural enterprises starting to focus on information technology. With the popularity of the Internet, many agricultural enterprises began to realize the importance of the construction of enterprise information, the vast majority of companies have access to the Internet; agricultural companies recognize the importance of network publicity, have to build a corporate image display, publishing product information portal; construction of a number of leading agricultural enterprises of agricultural products e-commerce platform for the trading of agricultural products, greatly reduce the transaction costs and improve corporate earnings. There are some leading agricultural enterprises and enterprise management, improve the level of information of the enterprises in the procurement, production, sales, marketing, finance and human resources management and other aspects of the use of ERP systems.

The state-owned farm land management information pilot made significant progress. Beginning in 2004, the Ministry of Agriculture annual allocations of part of the central government funds used to explore state-owned farm land information management, and the construction of state-owned land resource management system pilot in Guangdong, Heilongjiang and Hainan Reclamation. Seven years, the pilot unit according to the requirements of the land use, management and protection of state-owned farms, push forward the construction of farm management subsystem, system sets land management, agricultural production, social security, the subsidy policy, staff management in one of the farm business farming precise management of the land and improve the level of comprehensive utilization of land resources and farm management level of information.

\section{Professional Farmers Cooperatives Operating Information Technology}

Around the farmers' cooperatives starting to focus on information technology. Around the farmers 'professional cooperatives have established a website, cooperatives internal agricultural information can be released at any time through the website, you can achieve online trading, publishing agricultural news, and also the formation of the online Union to promote the standardization of the construction of farmers' professional cooperatives, standardized. Since 2009, Anhui Province, the implementation of farmers 'professional cooperatives construction project, the province's 1500 professional farmers cooperatives "Anhui farmers' professional cooperatives network", to achieve a "production in the community, marketing network, service exchange, resource sharing". As of the end of 2010, Gansu Province, has more 
than 6300 professional farmers cooperatives, in 2010, the Agriculture and Animal Husbandry Department of Gansu Province to help the province's 100 co-operatives to build a network information platform to achieve a cooperative digitization of information, management processes and product sales of electronic.

Professional farmer's cooperatives in the primary information services play an increasingly important role. "Eleventh Five-Year" period, China's development of farmer cooperatives momentum, the total amount of the rapid growth of farmers 'professional cooperatives, business areas continue to expand, is increasingly becoming an effective way to increase farmers' income. As of the end of 2010, the national farmers' professional cooperatives amounted to 379,100 , there is entrance farmers 29 million, accounting for about $11 \%$ of the total number of households. These farmers' professional cooperatives are widely distributed in cultivation, animal husbandry, agricultural, fisheries, forestry and other industries, members of the cooperative jointly engaged in the purchase of agricultural production, agricultural marketing, storage, processing, entrance farmers income is generally higher interbank household income than non-members more than $20 \%$.

\section{Conclusion}

In summary, the significant progress of China's agricultural and rural information construction, information technology applications in the field of agricultural production continued to deepen, the rapid development of information technology in agricultural operations, the agriculture management information to further promote agricultural services information technology steadily improved, as the "Twelfth Five-year "period of national agricultural and rural information work smoothly laid a good foundation.

\section{References}

1. Chen, X.: The evolution of agricultural informationization and countermeasures. Science and Technology Management Research (7), 437-03 (2009)

2. Yong, C.: To speed up the agricultural informationization construction to promote agricultural modernization development. Journal of Inner Mongolia Science and Technology and Economy (9), 63-64, 18 (2009)

3. Zhao, C.: Henan province rural informatization way and strategy analysis. Journal of Management Informationization in China 12(17), 81-83 (2009)

4. Du, X., Zhu, Q., Wen, H.: New rural informationization present situation and development countermeasures. Rural Economy (8), 95-98 (2009)

5. Huan, S.H., Sheoran, S.K., Wang, G.: A review and analysis of supply chain operations reference (SCOR) model. Supply Chain Management 9(1), 23-29 (2004)

6. Choi, T.Y., Dooley, K.J.: Supply networks and complex adaptive systems: control versus emergence. Journal of Operations Management 19(3), 351-366 (2001) 
7. Zhang, A.: What time thinking about the construction of speed up agricultural informationization. Journal of Agricultural Science and Technology (1), 17-18 (2007)

8. Yang, X.: Thinking about China's rural informatization construction. World Agriculture (3), 19-21 (2008)

9. Jiang, X.: Strategy analysis of agricultural informatization development. Journal of Agricultural Mechanization Research (3), 32-35 (2005)

10. Liu, W., Ma, X.: Agricultural information technology development research in the construction of new socialist rural. Agricultural Science of Anhui (12), 2911-2912 (2006) 